\title{
BANK OF SUSTAINABILITY; A BUSINESS APPROACH TO MOTIVATE PEOPLE TO ENGAGE WITH SUSTAINABILITY
}

\author{
Parisa Artin \\ Didasko Group, Australia \\ E-mail: parisa.artin.2017@gmail.com \\ Sorena Artin \\ Didasko Group, Australia \\ E-mail: sorena.artin.2017@gmail.com
}

Submission: 02/13/2019

Accept: 02/27/2019

\section{ABSTRACT}

Among all nation members of OECD, Australia is the highest greenhouse gas polluter. To solve this issue, Australian government has initiated some policies and incentives for the businesses to reduce their greenhouse gas emissions. However, individuals and households play a key role in greenhouse gas emissions as one fifth of Australia's greenhouse gas emissions are coming from the Australian households. It is required to provide effective extrinsic motivation to the people to embed sustainability into their daily life. "Bank of Sustainability" is a new business concept introduced in this paper to provide such motivation for involving individuals in sustainability. Bank of sustainability provides tangible advantages to its customers for their engagement with sustainable practices leading to a major behavioural change and positive movement to a more sustainable environment and society.

Keywords: Sustainability, Global Warming, Greenhouse Gas Emission, Household Sustainability, Motivation 


\section{INTRODUCTION}

Global warming, through rising greenhouse gas emissions, is not only impacting on human populations and ecosystems, it is also causing negative impacts on economic development (WEART, 2008). Commercial activities of businesses are contributing to global warming through unethical social and environmental behaviours.

Hillary (1995) believes that global warming is mainly caused by business and industry; and this could lead to between $5 \%$ to $20 \%$ decrease in global economic output (STERN, 2006). However, due to the increasing regulations and incentive schemes for the businesses, they have mainly accepted to implement some socially responsible and environmentally friendly practices under the rubric of Corporate Social Responsibility (CSR).

Also, businesses now are aware that the customers scrutinise their activities. So, adopting social and environmental practices to reduce their negative impacts on the ecology and community will bring them a competitive advantage (SMITH; OAKLEY, 1994; BIONDI et al., 2000; YUSOF; ASPINWALL, 2000; GERSTENFELD; ROBERTS, 2000; LEPOUTRE; HEENE, 2006; DEEGAN, 2007).

Solving global warming will improve the quality of human communities' lives and ecosystems. It is specially the case in Australia which is the highest greenhouse gas polluter among all the nation members of the Organisation for Economic Cooperation and Development (OECD) (AUSTRALIA'S GREENHOUSE GASES, 2015). $1.4 \%$ of global greenhouse gas emissions are generated by Australia (THE CLIMATE INSTITUTE, 2015). Considering the low population of the country, per person, Australia is one of the world's largest polluters. Based on the statistics, Australia's greenhouse gas emissions are nearly twice the OECD and more than four times the world average (AUSTRALIA'S GREENHOUSE GASES, 2015).

\section{OUR ROLE IN GLOBAL WARMING}

Playing a significant role in global warming by businesses doesn't exempt us from our responsibility towards our planet. As individuals, we need to take responsibility and do small sustainable actions every day to "meet the needs of the present without compromising the ability of future generations to meet their own needs." (BRUNDTLAND, 1987, p. 8). 
Each of us counts in solving the global warming and moving forward to a sustainable society. There are so many small individual practices which can contribute to sustainable development, such as sorting and disposing the wastes, using eco-cleaning services, cancelling junk mails to reduce paper wastes, donating the useful clothes and old stuff, using reusable shopping bags, turning off the unnecessary lights, turning off the tap while brushing the teeth etc.

Collectively, all these small activities play significant roles in creating a more sustainable community. It is our job to reconsider our lifestyle and start implementing social changes. Such changes take time, but it doesn't mean they are impossible. It is possible to make great positive impacts with all these negligible and small activities because if we adopt such practices consistently, all of them will become our daily habits after a while and change our behaviour and attitude towards the planet and people.

When individual behaviour changes, it creates the foundation for sustainability actions and adopting such actions will result in greater sustainable community (PAPPAS; PAPPAS, 2014). However, the main question raised here is that how we can motivate every individual to adopt such small sustainability practices in their daily lifestyle? This paper tries to answer this question from a business perspective.

\section{MOTIVATION}

Motivation determines what people will do (SCHAPER et al., 2013). Based on Shanks (2012), motivation is the act of providing motive which makes people to act. To encourage people to revise their daily routine behaviour to more sustainable one, we need to create a motivating environment.

Authors believe that if every individual receives the tangible benefits of the sustainable activities they adopt daily, there would be more courage and enthusiasm for them to implement sustainable practices consistently.

Based on Schaper et al. (2013), there are two types of motivation, intrinsic and extrinsic. Regarding sustainability, intrinsic (or internal) motivation could arise from different training programs to increase the people's awareness about the current global social and environmental issues. For example, if the education system in each country starts to teach the topic of sustainability from the early stages of 
students' life, it will help to increase their intrinsic motivation to practice more sustainable activities in their daily life.

As we can see, nowadays schools are increasingly involving the different sustainability topics in their curriculum. Also, there are some resources to help teachers, education providers, curriculum coordinators and principals to include sustainability in the schools' curriculum. The "Sustainability in School" portal is one of these resources which help to embed sustainability into the classrooms, schools and communities in Australia (SUSTAINABILITY IN SCHOOL, 2018).

Apart from intrinsic motivation, we need to provide some extrinsic (external) motivation for the people to get involved in sustainability adoption. An extrinsic motivation could be something like financial rewards or credits from the outside (SCHAPER et al., 2013).

If every individual could get tangible benefits from their adopted sustainability activities, they will show more readiness to do more voluntary sustainable activities. For example, as the government of Australia has been committed to reduce the greenhouse gas emissions to $5 \%$ below 2000 levels, they have initiated some tangible incentives for the businesses to reduce their greenhouse gas emissions (AUSTRALIAN GOVERNMENT, 2014).

For this purpose, the "Emissions Reduction Fund" targets the Australia's domestic emissions reductions and provides strong incentives to reduce the costs of businesses and their emissions to the environment (AUSTRALIAN GOVERNMENT, 2014).

Now the question raised here is that how the government of Australia could initiate similar incentives for individuals and households to practice more sustainable activities? Based on Fielding et al. (2011), a fifth of Australia's greenhouse gas emissions are coming from the Australian households.

So, there is a significant need to motivate individuals and households to practice more sustainable activities. Although there is a set of policies (through voluntary actions or pricing mechanism) initiated to improve the household's engagement with sustainability like installing efficient appliances or increased price of water and energy, it still requires fostering positive attitudes towards the sustainability (FIELDING et al., 2011). As suggested by Fielding et al. (2011), social 
norms which support sustainability need to be encouraged. Also, we need to find a way to overcome the financial limitations faced by households in adopting some sustainability practices (FIELDING et al., 2011).

\section{BANK OF SUSTAINABILITY}

In this paper, a business idea will be presented which offers an extrinsic motivation for the individuals and households to be more sustainable. As mentioned before, we need to offer some tangible benefits to the individuals who adopt sustainability practices in their daily life. This business idea is based on the common concept of a bank. As we all know, individuals and businesses save their money into a bank account to receive tangible benefits such as credit cards, accessing to home and business loans, insurances etc. The same trend could be applied to the engagement of people with sustainability. Against the financial banks which work with financial capitals (like money), "Bank of Sustainability" will work with social capitals.

Bank of Sustainability (BOS) is a social bank concept which provides tangible benefits to its customers. Instead of saving the financial capitals, customers of BOS will save their contributions towards the sustainability in their bank accounts. In the BOS system, there would be a scoring mechanism for each possible sustainable activity that every person can adopt in the daily life. Based on the scoring mechanism, customers of BOS will get credits for their engagement with sustainable practices.

For example, if an individual opens a bank account in BOS, based on the water bill uploaded, their average daily water use will be recorded in the bank account. Then, based on the common benchmark for the average daily water consumption, a target will be proposed to that customer to reach. If the customer could meet the proposed target within the required time, a credit or two or more (depending on the amount of water saved) will be recorded in their bank account. Same trend could be done with other household sustainable activities.

For further clarity, let's have a look on the below hypothetical example to find out how the BOS will give credits to its customers;

David is a single man living in a one-bedroom apartment in Sydney and based on his recent water bill, his water consumption is around 800 litres per day. He 
opens a bank account in BOS to get rewarded for his sustainability activities. He uploads his water bills and the bank realises that his water consumption is well over the average one. Based on the RWCC (2018), the average daily water consumption in Australia is 340 litres per person. Now, a target of 500 litres per day is introduced to David from the BOS to get one "Sustainability Credit". Next month, when the bank realises that he has met the offered target, one Sustainability Credit (SC) will appear in his bank account. Also, a new target of 340 litres per day will be introduced to him to get more SCs in the next month.

As mentioned before, same benchmarking and rewarding mechanism could be introduced for other sustainable activities. Some of the possible sustainable activities that can be rewarded are carbon footprint, electricity and gas consumption, fuel consumption, number of printed papers, donating to charities, blood donation, voluntary social activities etc.

For each of these practices, a benchmark and rewarding mechanism will be calculated and offered by the BOS to its customers. Based on the required target, customers will try to get as many SCs as possible to receive a higher "Overall Sustainability Credit". Customers' Overall Sustainability Credit (OSC) will be monitored every few months to make sure that they are adopting sustainable practices consistently and if they fail to adopt such practices, their OSC will be reduced gradually. In this way, the BOS customers will always make sure to be sustainable consistently and will control all their activities to impose less harms to the environment and society.

Now, the main question raised here is that how the customers could get tangible benefits from their OSC awarded by the bank of sustainability? Going back to the previous example, how David will be motivated to get more SCs and how his OSC will bring some competitive advantages for him?

\section{USING SUSTAINABILITY CREDITS}

Through the commonly known banking system, customers receive different financial services such as deposit their pay checks, take out different loans, set up saving accounts, receive helps and advice for the investment etc. Due to all these tangible benefits, people are motivated to open a bank account and save their money into it. Same functions need to be adopted for BOS to motivate people to 
open a "Sustainability Account" and receive tangible advantages through it. Authors believe that for this purpose, a collective agreement and will is required from the businesses and governments to give some competitive advantages to the people with good OSC.

In other words, customers of BOS need to see that some extra bonus or advantages are offered to them if they adopt more sustainable practices in their life. It is like a situation when you save more money in your financial bank account, you will receive more benefits like increasing your credit card's limit or receiving personal loans etc.

The following arguments discuss some of the possible tangible benefits that customers of BOS with high OSC could receive:

As we all know, the immigration office in Australia uses a point-test system to issue some permanent skilled visas (AUSTRALIAN GOVERNMENT, 2018). This system is actively reviewed by the Australian Government. Apart from the main requirements such as age limit, employment history, qualifications etc., a small portion of this point system could be allocated to OSC of the interested applicants. In this way, the Australian Government could limit the new immigrants to the sustainable individuals and households who have shown a good record of adoption of sustainable practices through their BOS accounts.

Based on the statistics, the skill stream visa accounted for $67.3 \%$ of the total Australia's 2016-2017 migration programme outcome (AUSTRALIAN GOVERNMENT, 2017). Considering some few points for the migration applicants' engagement with sustainable activities could contribute significantly to the Australia to meet its targets in reducing the greenhouse gas emissions every year.

Priority in employment is another competitive advantage that could be offered to people with high sustainability credit. In this way, job applicants with higher sustainability credit in their BOS account will have more chances to be recruited. Employers could consider some employment priorities for the sustainable applicants leading the sustainable employees recruited by the companies. To receive more SC, such employees will always try to adopt more sustainable activities in their daily life including when they are at work. This helps the companies to save more resources and become more sustainable as the sustainable people will create a sustainable 
culture in the workplace as well. And developing a sustainable culture in the businesses will lead to better engagement with sustainable practices (SALIMZADEH; COURVISANOS, 2015).

Sustainable people would use more public transport options to reduce the private cars' emissions and petrol usage. Through their BOS accounts, they could receive SC for this action. Hence, offering some discounts for purchasing public transport tickets will motivate them more to commute using public transport systems. One of the competitive advantages that government and public transport companies could offer to sustainable individuals is to offer some discounts and vouchers for using public transports. If the sustainable people receive such advantages, they will show more enthusiasm in using public transport leading to less traffic jams, cleaner air, less petrol usage and less greenhouse gas emissions.

Receiving some discounts to buy sustainable goods like solar panels, gift shopping vouchers, paying less tax, discounts for some financial services like a home mortgage's interest rate are some of the possible competitive advantages that could be offered to BOS customers with high SC.

\section{CONCLUSIONS}

To survive in the planet, it is required to maintain what humans need or want from the environment like clean water and fresh air. As societies and communities move towards the sustainability path, markets try to provide a range of environmentally oriented products and services. In this regard, national governments use different tools and resources to develop sustainability adoption for businesses, whereas, the prominent role of individuals and households in the progression of sustainability has been neglected (SALIMZADEH, 2017).

Although political and economic drivers at the national and international levels are critical for setting the sustainability framework, the key role of people and households should not be neglected in the transformation of the communities toward sustainability. Recent organisational and management studies have paid much attention to the concept of Corporate Sustainability (CS), but the adoption of sustainability practices within households has received limited attention and study.

Global warming and climate change have been very influential in business sustainable development (POTTS, 2010) and changing the way that governments 
plan for such sustainability (SALIMZADEH, 2016). However, individuals and households should not be excluded from the government's planning for sustainable development. In Australia, household's contribution to greenhouse gas emissions is $20 \%$ (FIELDING et al., 2011). To motivate individuals and households to reduce their greenhouse gas emissions, tangible benefits should be awarded to those who adopt sustainability practices.

Bank of sustainability is an innovative business idea which could provide such motivation to the individuals and households to adopt sustainable practices in their daily life. This social bank needs to receive adequate support from the governments and businesses. As shown in figure 1, through this bank, people could save their engagement with sustainability and gain sustainability credits whenever they do something to protect the environment or support the society.

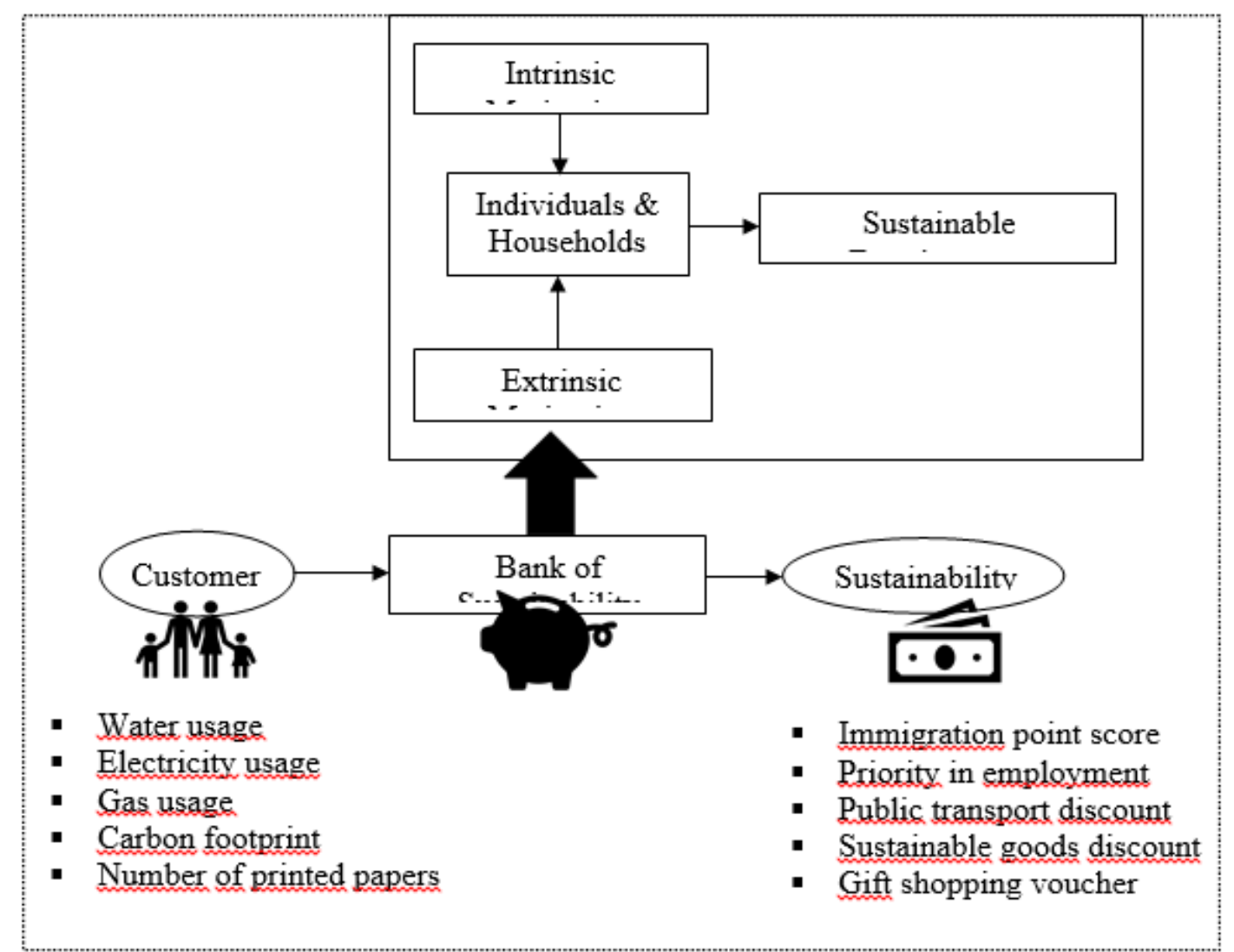

Figure 1: Conceptual Framework of Bank of Sustainability Source: developed by authors for this paper

Sustainable practices of customers (such as reducing water, electricity and gas usage) are recorded in their bank accounts. Based on their closeness to the common benchmarks, one or two or more sustainability credits are offered to them. These credits are accessible through their bank account and they can use them for 
INDEPENDENT JOURNAL OF MANAGEMENT \& PRODUCTION (IJM\&P)

http://www.ijmp.jor.br

v. 10, n. 3, May - June 2019

ISSN: 2236-269X

DOI: $10.14807 /$ ijmp.v10i3.1005

different purposes such as receiving some discount when buying some sustainable goods like solar panels.

Calculating a benchmark for all the possible sustainable activities is a very time-consuming process. Even for some of the social activities like blood donation, it is very difficult to calculate the common benchmarks. However, receiving credits and benefits for the main activities of less usage of natural resources could lead to significant results in solving the global warming. Also, the idea of BOS is a very newly born one and needs more research and support. So, it could be the future research topics to investigate how each sustainability practice could be quantified in the format of numbers then transformed to the social credits.

\section{REFERENCES}

AUSTRALIAN GOVERNMENT, DEPARTMENT OF ENVIRONMENT. (2014) Reducing Australia's emissions, Commonwealth of Australia. Retrieved 16 July 2018 from http://www.environment.gov.au/climate-change/government/emissionsreduction-fund/publications/reducing-australias-emissions

AUSTRALIAN GOVERNMENT, DEPARTMENT OF IMMIGRATION AND BORDER PROTECTION. (2017) 2016-2017 Migration Programme Report. Retrieved 19 July 2018 from https://www.homeaffairs.gov.au/about/reports-publications/researchstatistics/statistics/live-in-australia/migration-programme

AUSTRALIAN GOVERNMENT, DEPARTMENT OF HOME AFFAIRS. (2018) The Points $\quad$ Table. $\quad$ Retrieved 19 July 2018 from https://www.homeaffairs.gov.au/visas/supporting/Pages/skilled/The-points-table.aspx

AUSTRALIA'S GREENHOUSE GASES. (2015, August 2) Retrieved from http://www.wwf.org.au/our_work/people_and_the_environment/global_warming_and _climate_change/science/australia_greenhouse_gases/

BIONDI, V.; FREY, M.; IRALDO, F. (2000) Environmental management systems and SMEs. Greener Management International, y. 2000, n. 29, p. 55-79.

BRUNDTLAND, G. (1987) Our common future: Report of the world commission on environment and development. Oxford: Oxford University Press.

DEEGAN, C. (2007) Australian Financial Accounting. Roseville: McGraw-Hill.

FIELDING, K. S.; THOMPSON, A.; LOUIS, W. R.; WARREN, C. (2011) Sustainability decisions in Australian households. AHURI Research \& Policy Bulletin, n. 140, ISSN: 1445-3428.

GERSTENFELD, A.; ROBERTS, H. (2000) Size matters: Barriers and prospects for environmental management in small and medium-sized enterprises. In: Hillary, R. (ed.), Small and medium-sized enterprises and the environment: Business imperatives (p. 106-118). Sheffield: Greenleaf Publishing in association with GSE Research.

HILLARY, R. (1995) Small firms and the environment: A groundwork status report. 
Birmingham: Groundwork Foundation.

LEPOUTRE, J.; HEENE, A. (2006) Investigating the impact of firm size on small business social responsibility: A critical review. Journal of Business Ethics, v. 67, n. 3, p. 257-273.

PAPPAS, J. B.; PAPPAS, E. C. (2014) The sustainable personality: Values and behaviours in individual sustainability. International Journal of Higher Education, v. 4 , n. 1, p. 12-21.

POTTS, T. (2010) The natural advantage of regions: Linking sustainability, innovation and regional development in Australia. Journal of Cleaner Production, v. 18, n. 8, p. $713-725$.

RIVERINA WATER COUNTY COUNCIL (2018) Average water use. Retrieved July 16, 2018, from https://www.rwcc.nsw.gov.au/save-water/average-water-use

SALIMZADEH, P. (2016) SMEs engagement with sustainability in Australia. In: CLARK, D.; MCKEOWN, T.; BATTISTI, M. (ed.), 2016 rhetoric and reality; Building vibrant and sustainable entrepreneurial ecosystems. Australia: TILDE University Press, ISBN: 978-0-7346-1257-1.

SALIMZADEH, P.; COURVISANOS, J. (2015) A conceptual framework for assessing sustainable development in Regional SMEs. Journal of Environmental Assessment Policy and Management, v. 17, n. 4, DOI: 10.1142/S1464333215500398.

SALIMZADEH, P. (2017) Effective factors on sustainability adoption in Regional Australian SMEs; A case study of Ballarat, World Journal of Management, v. 8, n. 1, p. 32-44.

SCHAPER, M.; VOLERY, T.; WEBER, P.; GIBSON, B. (2013) Entrepreneurship and small business, $4^{\text {th }}$ Asia Pacific edition. Milton: John Wiley \& Sons.

SHANKS, H. N. (2012) Management and motivation. In: BUCHBINDER, S. B.; SHANKS, H. N. (ed.), Introduction to health care management (p. 23-35). Sudbery MA: Johns \& Bartlett Publisher.

SMITH, P.; OAKLEY, E. (1994) A study of the ethical values of metropolitan and nonmetropolitan small business owners. Journal of Small Business Management, v. 32 , n. 4 , p. $17-27$.

STERN, R. (2006) Stern review on the economics of climate change. Retrieved September 16, 2013, from ICAEW: http://www.icaew.com/en/library/subjectgateways/environment-and-sustainability/stern-review

SUSTAINABILITY IN SCHOOLS. (2018) Getting started with sustainability in schools. Retrieved July 16, 2018, from https://sustainabilityinschools.edu.au/

THE CLIMATE INSTITUTE. (2015) What do the numbers really mean. Retrieved July 9, 2018, from climateinstitute.org.au

WEART, S. (2008) The discovery of global warming: Revised and expanded edition. Cambridge: Harvard University Press.

YUSOF, S.; ASPINWALL, E. (2000) Total quality management implementation frameworks: A comparison and review. Total Quality Management, v. 11, n. 3, p. 281-294. 